\title{
Development of a downstream emergency response service for flood and related risks in Romania based on satellite data
}

\author{
Gheorghe Stancalie ${ }^{1, a}$, Vasile Craciunescu ${ }^{1}$ and Anisoara Irimescu ${ }^{1}$ \\ ${ }^{1}$ National Meteorological Administration, 97 Soseaua Bucuresti-Ploiesti, sector 1, 013686, Bucharest, Romania
}

\begin{abstract}
Recently, the National Meteorological Administration initiated and started to implement user-driven services, based on satellite remote sensing and geo-information capacities. The paper presents this downstream emergency response service whose aim is to provide updated and accurate cartographic information in river flood prevention and post-crisis phase. The service is targeted to develop an interoperable framework for the management of the available geo-information using cutting-edge techniques and satellite data in order to provide high quality and accurate spatial products. An appropriate methodology was developed and tested, in order to process the optical or radar satellite imagery, with medium and high range spatial resolution, to rapid mapping the flood extent, to integrate the information in a GIS environment and finally to obtain standardized, cartographic products. The service is able to provide customized flood geospatial products (updated reference maps for the area affected, near real-time flood delineation maps, maximum flood extent maps, flooded area classification, flood evolution maps, damage assessment maps and reports) tailored to specific users and featuring near-real time delivery. A dedicated geo-portal, was developed to display, query, analyse and retrieve the spatial products. The end-users are able to access the system using a simple web browser to view and query the flood related product archive or download the selected products.
\end{abstract}

\section{Introduction}

The Sendai Framework for Disaster Risk Reduction 2015 - 2030 highlighted that natural disasters are of increasing frequency and severity in the modern world. Impacts of disaster events on human lives and the economy are increasing every year due to growing urbanisation and an increase in the number and severity of extreme weather events. Floods are one of the most frequent natural hazards and occur in almost every country.

The extreme floods in Europe could generate losses more than double by 2050 , because of climate change and socio-economic development [1].

Floods represent a hazard with high frequency and magnitude in Romania, especially on rivers originating in the Carpathian mountain area. The most frequent river floods in Romania occurred by over passing the current levels or the occurrence of the torrents due to the abundant long term precipitations, the rapid melt of the snow cover, ice jams and the landslides. To these causes other favorable factors, can be added like the degradation or lack of dams.

Romania is a flood hotspot in Europe, which experienced significant human and economic losses in the last decade [2]. Since 2000, Romania has been affected by 55 natural disasters from which 34 were floods $(62 \%)$, according to the International Disaster Database: http://www.emdat.be/disaster_list/index.html.
Heavy rain in April and May 2005 caused the worst floods since 50 years in Romania. The floods and storms in Romania, killed 76 people, caused around 1.66 billion Euro in damage, affected about 656,392 ha agricultural land, $10,420 \mathrm{~km}$ roads, $23.8 \mathrm{~km}$ of railway, 9,113 bridges and foot bridges and contaminated 90,394 wells [3].

In 2006, the extreme floods between April and August were among the most devastating natural disasters from recent Romanian climate history (the most devastating during the observation period 1840-2006 [4]. Although there were no human victims, the extent of the damage and the number of evacuated people surpassed by far the floods of 1970, one of the worst floods that hit Romania. Estimations have shown that during April - May interval, 12 counties were affected, and the total economic damage was over $1 \%$ from Romanian GNP [3].

The 2012 Romanian floods were the result of an extreme weather event that struck Romania in late May 2012. The south-east of the country, was most affected, 209 localities were flooded, other 24 being isolated.

In June 2013 severe floods, mainly caused by torrential rain, affected 13 counties in Romania. The most affected river basins were Siret, Prut, Barlad, upper and middle Mureş and upper and middle Olt.

The heavy rains registered in some areas in Romania on May 26, 2015, caused floods in Maramures and Salaj counties.

The climate change scenarios for Romania show an increase of the extreme hydrological and meteorological

\footnotetext{
${ }^{\mathrm{a}}$ Corresponding author: gheorghe.stancalie@meteoromania.ro
} 
phenomena like floods, landslides and droughts [5]. These scenarios, together with the increase of population in vulnerable urban areas suggest that preventive and protective actions should be taken at the same time with thorough preparation for disaster response.

These recent flood events have confirmed the necessity for modern and effective flood protection measures, considered as a part of an integrated flood risk management. In this respect the Romanian governance structure supports the development and implementation of integrated flood risk management; both the extent and coherence of flood risk governance has increased in recent years.

Integrated flood risk management aims to reduce the human and socio-economic losses caused by flooding while taking into account the social, economic and ecological benefits from floods and the use of flood plains or coastal zones. The need for the adoption of a holistic integrated approach to managing flood risks has been reflected in the Directive 2007/60/EC on the assessment and management of flood risks.

The paper aims to present a downstream service for flood and related risks based on a complex, accurate and updated reference GIS geodatabases, containing different information layers such as land use/land cover, roads, rivers, water basins, administrative boundaries, digital elevation models, archive optical and synthetic aperture radar satellite imagery, in-situ data and auxiliary data. The web-based service provides value-added products for each flood related disaster management phase (preparedness /prevention, emergency response and recovery) to more effectively support the central and local authorities in making decisions in developing, implementing and monitoring policies. The downstream emergency response service purpose is to enable the significant socio-economic benefits and provide significant strategic and political benefits for Romania.

The downstream service for flood and related risks has been implemented on a dedicated geoportal in the framework of the GEODIM project (Platform for Geoinformation in Support of Disaster Management: http:/geodim.meteoromania.ro) financed by the Romanian National R\&D Program 2012 - 2016.

\section{Earth Observation satellites and geo- information systems contribution in flood management}

Earth Observation (EO) satellites proved to be a powerful tool to generate uniform information across a range of countries and covering a wide span of flood risk scenarios. It supports the generation of objective, coherent information about risk that is easy to update and difficult to challenge. Applied in a systematic way, satellite EO can help create consistent and comparable information to measure implementation of the post-2015 framework for disaster risk reduction, when measures can be concretely observed [6].

Satellite observations can supply regular, detailed updates on the status of flood hazards on a regional, or national basis. EO satellite data are a complementary data source to in-situ data, but in some cases it may be the only source of information, either because of limited or lacking in-situ information or because satellites offer a unique means of monitoring that cannot be affected by the hazards observed.

The synergistic use of observations from multiple satellite sensors, with careful consideration of the specific space/time resolution and different revisit times of each satellite allows an optimal flood monitoring.

More than a hundred EO satellites are in operation at any one time [6], hosting a diverse range of sensor types that utilise different parts of the electromagnetic spectrum and different techniques to provide a range of measurements from space. Much of these data are available freely and openly for any purpose and ready for application by the Disaster Risk Reduction community.

Most EO satellites orbit the Earth over the poles and collectively offer daily access to most points on the globe for both optical and radar imagery.

Presently, satellite imagery has a major contribution to all the phases of the emergency flood management process. Space-based information in support of disaster monitoring can be obtained through the International Charter on Space and Major Disasters, Copernicus Emergency Management Service (EMS) and the United Nations Platform for Space-based Information for Disaster Management and Emergency Response (UNSPIDER). All these services offer unified systems of space data acquisition and delivery to the countries affected by natural or man-made disasters, with a worldwide coverage.

The integration of remotely sensed data and other spatial and non-spatial data within the GIS environment are able to produce series of thematic maps which was used to generate a geospatial database for flood risk analysis and assessment.

\section{Emergency response service for flood and related risks in Romania}

The emergency response service for disaster management, included floods and related risks, was designed and developed by a consortium made up of relevant Romanian governmental institutions and companies in the framework of several research projects, following the principles of the Copernicus downstream services and the end-users requirements [7]. The main aim of the national downstream service for emergency response is to reinforce the Romanian capacity to support disaster management based on geo-information, covering all phases of a disaster cycle: prevention, preparedness, response and recovery. The emphasis is put on valueadded, validated products and services for each phase of the disaster management.

The service is targeted to develop an interoperable framework for the management of the available geoinformation using cutting-edge techniques and satellite data in order to provide, in a fast manner, high quality and accurate spatial products. The products are generated using adapted and improved processing algorithms. 
Taking into account the hydrological regime of the Romanian rivers, the satellite imagery can be very effective for the monitoring of the moderate and major floodplains, the most dominant in Romania. Due to the technical limitations (cloud cover in case of the optical imagery), and relatively low temporal and spatial resolution in case of radar imagery), the satellite data is not so useful for of the small floods or the flash floods mapping.

\subsection{Satellite data}

The service is based on the acquisition, processing and analysis, in rapid mode of satellite images.

Three sources of satellite data are considered for each of the service activation:

- Free satellite data available on public repositories (e.g. MODIS, Sentinel 1A, Landsat 8, Landsat 7 ETM+, SPOT VGT, PROBA-V);

- Satellite data or flood masks from the Copernicus Emergency Management Service (EMS) or International Charter "Space and Major Disasters" obtained via Romanian General Inspectorate for Emergency Situations (IGSU).

- Medium and high spatial resolution satellite data from commercial providers (FORMOSAT-2 (2m), SPOT-5 (2.5m-5m), Rapid Eye (5m), Terra SAR-X (1m), SPOT-6/7 (1.5m), Pleiades-1A/B (0.5m), GeoEye-1 $(0.5 \mathrm{~m}))$.

Most satellite derived products for flood management have been obtained from the Moderate Resolution Imaging Spectroradiometer (MODIS) onboard the TERRA/AQUA NASA spacecraft. MODIS radiometer scans the Earth with 36 spectral bands extending from the visible to the thermal infrared wave lengths. The first seven bands are designed basically for remote sensing to capture features on the Earth surface at for bands 1 and 2 and 500 metres for bands 3 to 7 . The MODIS instrument views the entire Earth surface every one to two days with a swath width of $2330 \mathrm{~km}$.

Daily Terra MODIS surface spectral reflectance MODIS products (MOD09GQ with $250 \mathrm{~m}$ spatial resolution for bands 1-2 and MOD09GA with $1 \mathrm{~km}$ and $500 \mathrm{~m}$ spatial resolutions for bands 3 to 7) were automatically downloaded from NASA FTP servers. Both products are already corrected for atmospheric conditions such as gasses, aerosols, and Rayleigh scattering.

Due to the good temporal frequency the MODIS data have been widely used for flood mapping, flood assessment, warning, vulnerability analysis and mitigation.

LANDSAT 5Tm $(30 \mathrm{~m})$, LANDSAT 7 ETM+ $(15 \mathrm{~m})$ and LANDSAT $8(15-30 \mathrm{~m})$, downloaded from USGS GLOVIS portal, have a relatively low temporal resolution. Due to the cloud cover only few LANDSAT scenes can be used for flood monitoring. However, the information was very useful for validation purposes.

The new family of Sentinels missions, specifically designed for the operational needs of the Copernicus programme, can be used to assess the extent of flooded areas and the impact on human, economic and environmental loss.

The Sentinel-1A mission (launched on the $3^{\text {rd }}$ of April 2014) includes a C-band synthetic aperture radar imaging, operating day and night, regardless of the weather, in four exclusive imaging modes with different resolution (down to $5 \mathrm{~m}$ ) and coverage (up to $400 \mathrm{~km}$ ). Sentinel-1A satellite is able to map the entire world once every 12 days. The two-satellite constellation will have a repeat frequency (ascending/descending) of 3 days at the equator, and is able to provide coverage over Europe, in 1-3 days, regardless of weather conditions.

The radar data will be delivered to Copernicus services within an hour of acquisition.

SAR's inherent capability to observe during cloud cover and Sentinel-1's frequent revisits makes it ideal for flood monitoring.

Sentinel-2 (launched on the $23^{\text {rd }}$ of June 2015) is a wide-swath, high-resolution, multi-spectral imaging mission, supporting Copernicus Land Monitoring studies, including the monitoring of water cover, as well as observation of inland waterways and coastal areas. The Multispectral Instrument (MSI) can sample 13 spectral bands: four bands at $10 \mathrm{~m}$, six bands at $20 \mathrm{~m}$ and three bands at $60 \mathrm{~m}$ spatial resolution.

The acquired data, mission coverage and high revisit frequency provides reliable geoinformation at local, regional, national and international scales. Sentinel2 data is complementary to existing missions including LANDSAT and SPOT.

\subsection{Specific methods for satellite-based flood extent mapping}

The most efficient method for the water identification and mapping depends on the type of available satellite information, in the optical or radar spectral domain, as well as on the spatial resolution this information could provide.

The key issue of rapid mapping is to offer to the end user accurate situation maps in a shortest possible time. For operational purpose, in case of extreme flood an efficient processing procedure means a simple, fast and reliable one.

\section{A. Optical satellite imagery}

To precisely map the flood water extent, reference pre-flood images over the same areas are needed to extract normal water conditions and then compared to the water extent during the flood time.

For optical multispectral images the most used methods belong to the following categories:

(1) Spectral bands: The algorithms are based on water spectral pattern analysis, and water bodies are identified by applying thresholds to one or more spectral bands [8].

The pixel-based water delineation includes several steps: decomposition of the image into sub images according to spectral reflectance patterns; identification of best threshold value; delineation of associated pixels, 
refinement with elimination of unclassified or noise pixels and masking out.

Due to spectral mixture of ground objects caused by low spatial resolution water extraction by spectral patterns needs to be combined with some other measures such as level of reflectance in a shortwave infrared (SWIR) band.

(2) Classification: These methods apply supervised or unsupervised algorithms to extract water bodies from multispectral imagery.

The supervised classification uses examples of the information classes called "training sites", follows by signature analysis for each information class; finally the image is then classified by examining the reflectance for each pixel and making a decision about which of the signatures it resembles most. For supervised classification, the most notable methods are maximumlikelihood classifiers, decision trees, artificial neural networks and support vector machines.

The unsupervised classification does not require analyst-specified training data, but examines a large number of unknown pixels and divides into a number of classed based on natural groupings present in the image values. For unsupervised classification, the most common methods include the K-means and iterative selforganizing data analysis (ISODATA) [9, 10].

These approaches may achieve higher accuracy than spectral band methods under some circumstances; however, expert experience or existing reference data are required to select appropriate training samples, which prevents these methods from being applied over large areas [11].

(3) Water indices (WIs): These methods combine two or more spectral bands (mainly the shortwave infrared (SWIR), near-infrared (NIR) green and red spectral bands) to develop a suitable band rationing technique to enhance the discrepancy between water bodies and land and surface water changes [12, 13, 14].

Different WIs have been used, based on combinations of spectral bands: NIR-SWIR (800 nm vs. $1640 / 2130 \mathrm{~nm})$ and NIR-NIR (800 nm vs. $1240 \mathrm{~nm})$.

Good results have been obtained using the Normalized Difference Vegetation Index (NDVI), Normalized Difference Water Index (NDWI) [15] and the modified NDWI (MNDWI) [16] defined as:

$$
\begin{aligned}
& N D V I=(\rho 2-\rho 1) /(\rho 2+\rho 1) \\
& N D W I=(\rho 2-\rho 4) /(\rho 2+\rho 4) \\
& N D W I=(\rho 2-\rho 4) /(\rho 2+\rho 4)
\end{aligned}
$$

Where: $\rho 1$ represents the reflectance for the red band (e.g. MODIS band2, Landsat TM/ETM+ bands band 3, Landsat 8 OLI band 4), $\rho 2$ - the reflectance for the green band (e.g. MODIS band 4 or Landsat TM/ETM+ bands 2 ), $\rho 4$ - the reflectance for the NIR band (MODIS band 2 or Landsat TM/ETM+ band 4) and 5 the reflectance for SWIR (e.g. MODIS band 5, Landsat (TM) band 5 and Landsat 7 ETM+ band 5, Landsat 8 OLI band 6).

In the NDWI or MNDWI images the positive data values are typically open water areas; while the negative values are typically non-water features. Like NDVI,
NDWI or MNDWI have a native scaling of -1 to +1 . These products offer a means to view water bodies and may be useful for assessing flooding impacts. The NDWI products can be used in conjunction with NDVI change products to assess context of apparent change water areas. It was noticed that MNDWI has a more stable threshold than other WIs.

The difficulties associated with water body extraction from satellite imagery using WIs that are based on the thresholding method, include: (1) inefficient identification of mixed water pixels; (2) confusion of water bodies with background noise; and (3) variations in the optimal water extraction threshold that depend on the characteristics of an individual scene.

The validation procedure of mixed water pixels takes into account not only their spectral characteristics, but also their topological (spatial) connections.

\section{B. Radar SAR satellite imagery}

Radar images (Envisat ASAR, Radarsat-2, Terra SAR X, COSMO-SkyMed and Sentinel 1) are typically best data for flood detection because are not affected by weather conditions.

The pixels belonging to flooded areas have lowest values as the return signal from smooth water surface is weak. Thus in many cases water determination on radar images can be well defined through the image thresholding procedure. Simply setting a threshold frequently causes some overestimations in water patches determination, as shadows and part of speckle noise are also attributed as lowest intensity values. Pixel-based water delineation based on simple thresholding may therefore require substantial cleansing and refinement of the mapping results. In case of very high resolution very high resolution (VHR) SAR data, in urban and forested areas the detection of standing water is disturbed by the presence of objects that prevent remote sensing or alter the obtained products (like layover, shadowing effects).

For rapid flood detection [17] a split-based semiautomatic thresholding procedure was used which combines histogram thresholding and segmentation based classification, specifically oriented to the analysis of SAR satellite data. The object-based method includes 3 modules sequentially activated: segmentation, water mask extraction, flood extraction and refinements. The method requires pre and post event satellite data for validation and refinements.

Another used method is the multi-temporal segmentation approach [18]; the procedure is based on the image segmentation technique, which allows identifying homogeneous regions in order to extract a reliable backscattering value, and on the use of an electromagnetic model to interpret the radar return from the image segments. The image segmentation techniques includes: point, line, and edge detection, thresholding segmentation region, segmentation using morphological image processing. The context of mathematical morphology as a tool for extracting image components those are useful in the representation and description of region shape, such as boundaries and skeletons. 


\subsection{Workflow}

The International Charter "Space and Major Disasters" provides both raw satellite imagery and spacebased products. In the case of Romania, the satellite images were reprojected into the national reference grid, namely Stereographic 1970 (EPSG:31700). The water mask was extracted from satellite imagery either manually (using visual photointerpretation) or semiautomatically (by applying different image classification algorithms, followed by the visual check of the results).

In order to obtain a more accurate result, the water mask is further processed by integrating the digital elevation model (DEM), with an adequate spatial resolution.

For the elaboration of the flood satellite-derived products different GIS thematic information layers are added to: geomorphological maps, the boundaries of the administrative units, hydrografical network of permanent water bodies, roads network, localities, geographical names, land use/land cover, etc.

The Copernicus Emergency Management Service (EMS) provides flood space-based products, like water masks. The water mask, is reprojected into the national cartografic grid and then is thoroughly edited in order to eliminate its errors inherent to the automatic extraction. The correction precedure uses the comparison with the national raster and vector thematic geodatabase.

In the case of free satellite data available on public repositories or aquired from commercial providers the methodolgy includes:

- image pre-proecessing: geometric correction and geo-referencing in the STEREO 70 map projection system, image improvement (contrast enhancing, slicking, spectral band combinations and re-sampling operations);

- water detection and water-mask extraction: using different methods as presented in the previous subchapter;
- final geospatial product achievement using different GIS thematic info-layers.

The image processing was done using the ERDAS Imagine and ArcView 10.1 softwares.

The entire workflow was fully optimized and usually the final products are obtained 8-24 hours after the satellite image acquisition. The real processing time is around 1-2 hours, the major delay is related to the processing steps for the raw image, done by the satellite operator and data transfer. The flood mapping process is presented in Figure 1.

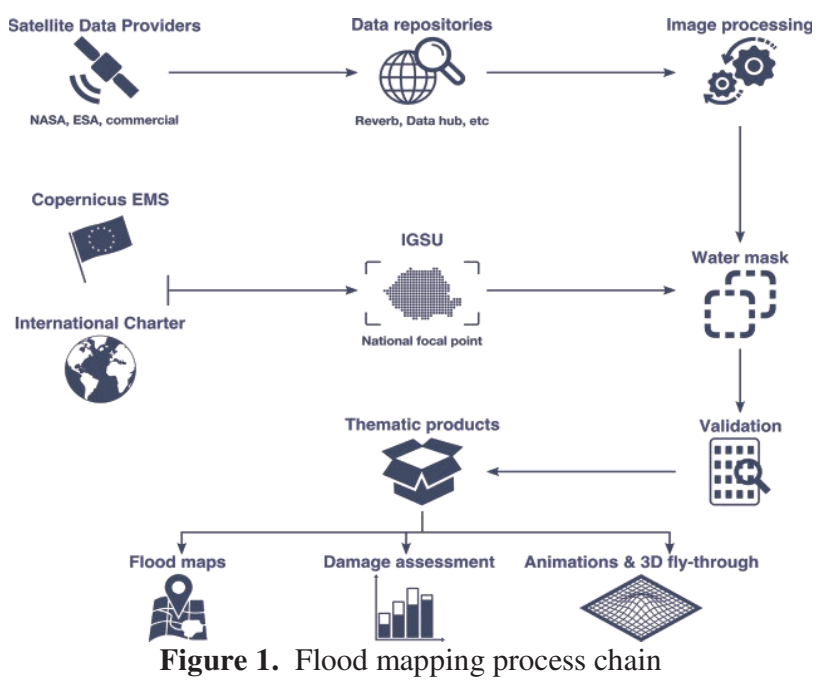

The service can provide a number of on-demand geospatial products:

- Reference maps: updated reference maps for the area affected by floods.

Near real-time flood delineation maps: represent a fast way of representing the flood affected areas in a cartographic form. Figure 2 presents an example of near real-time flood delineation map for the Galati county in the Eastern part of Romania on 30.06.2010. The water
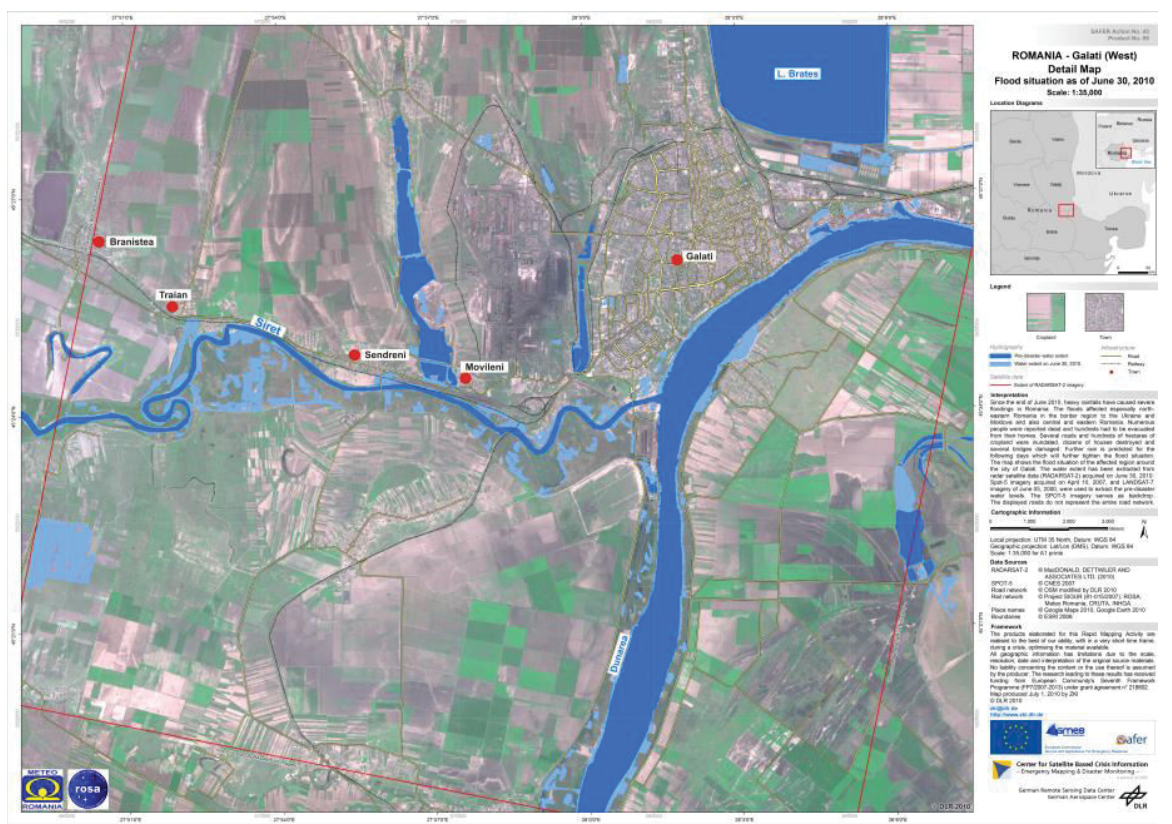

Figure 2. Example of a near real-time flood delineation map 
mask is derived from RADARSAT 2 satellite data and integrated in a GIS environment to produce a useful "snapshot" showing the area covered by the flood water at a given time during the flood episode and to easily depict the affected and endangered areas and infrastructure elements [19].

- Non real-time flood delineation maps: similar with the previous product, it's presenting the same information but in a more refined way. The cartographic quality may be enhanced and the products look more homogenous.

\section{The Geoportal}

A dedicated geoportal based on free and open source software and following a distributed architecture (Figure 3), was developed for an efficient access to geospatial flood-related products developed in the frame of the GEODIM project (Platform for GeoInformation in Support of Disaster Management).

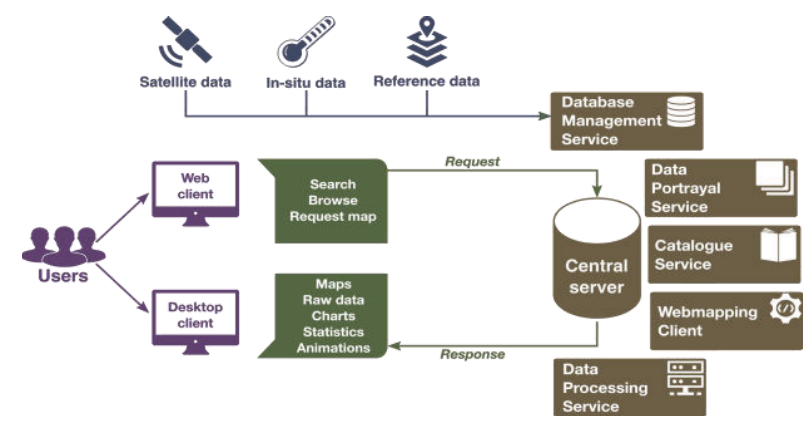

Figure 3. GEODIM geoportal architecture.

The system design was based on end-users requirements and well-established national and international bodies/initiatives. The following relevant European initiatives were taken into account when formulating the requirements: INSPIRE, SEIS and
Copernicus. The main components of the system are:

- Database management service;

- View service portal: allow users to view the spatial datasets stored in geospatial database. The service is an implementation of the ISO 19128/OGC Web Map Service (WMS) specification and is compatible with the INSPIRE Profile of ISO 19128. OGC Styled Layer Description (SLD) that is used as styling language.

For performance purposes, cached versions, based on OGC standard [OGC 07-057r7] - Web Map Tile Service (WMTS), of the service were also implemented.

- Data access service (download): provides interfaces allowing requests for the spatial datasets, raster and vector, stored in the geospatial database. The interface for vector data access is based on the OGC Web Feature Service specification. The interface for raster/coverage data access is based on the OGC Web Coverage Service specification with support for the WCS Earth Observation Application Profile (EO-WCS).

- Discovery service (catalogue service web): provides interfaces allowing discovery of the data stored in geospatial database. The interface for discovery of geospatial data is based on the OGC Catalogue Service Web. The service has support for metadata profiles based on ISO 19115, ISO 19139 and Dublin Core.

Web mapping client: allows the users to analyse the reference database and the flood maps in a GIS environment. The application has a simple user interface, with several functional areas (Figure 4).

Depending on the privileges, the end-users are able to access the system using a simple web browser (like Google Chrome or Mozilla Firefox) to:

- View and query the flood related product archive;

- Download the selected products;

- Validate the products.

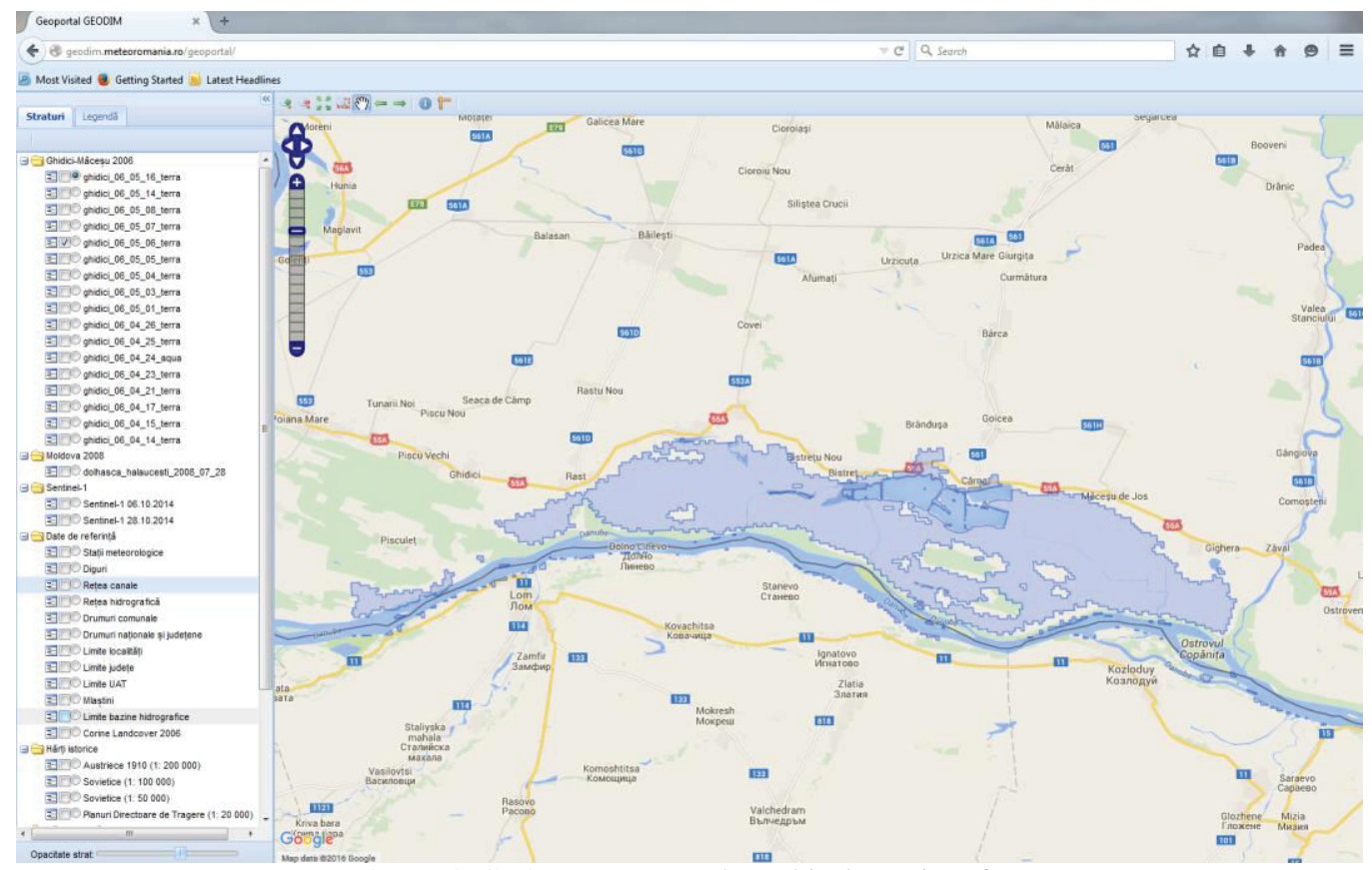

Figure 4: GEODIM geoportal graphical user interface 


\section{Conclusions}

For Romania, floods represents the most natural damaging events. The April 2000 floods in the Western part of the country represents the starting point in creating a service/system that can be used to map and monitor the flood evolution based on satellite images.

The satellite remote sensing data can offer qualitative information for a large areas, inaccessible by traditional ways in many times. The satellite data and geo-information systems techniques have an important contribution in managing flood connected phenomena by:

- detection of new flood events and public warnings;

- flood hazard mapping;

- rapid-response flood mapping and measurement.

Various processing techniques have been developed and tested, in order to process the raw data (satellite optical or radar, with, medium and high range spatial resolution, within 8-24 hours after the satellite images were acquired, to rapid mapping of event extent and finally integrate the information related to hydrometeorological events into useful, standardized, cartographic products. Beside the maps of the risk exposed areas, phenomenon extent evolution, 3D flythrough and different animations were produced to get a more complex perspective on phenomenon dynamic and dimension.

In Romania, since 2000, a large numbers of products have been produced. The results can be quickly disseminated, in digital form via Internet, using a dedicated webpage.

The downstream emergency service, implemented in the frame of the GEODIM project, will strength the collaborative approaches between the existing expert institutions/groups in the domain of geo-information applications for disaster management and will contribute to the availability of critical information for the decisionmakers and other end-users in near-real time.

The service allows the storage, management and exchange of raster and vector information and also related ancillary data for flood monitoring activities. This service contributes to regional quantitative risk assessment.

The future work is related to a better communication with the end-users, identification of new data sources and an extension of the service to cover other types of disasters,

The development of an online dedicated flood mapping service, has the potential to improve the flood management and to help the implementation of flood mitigation programs in Romania.

\section{References}

1. Brenden J., Hochrainer-Stigler S., Luc Feyen L., Aerts J., Mechler R., Wouter Botzen W. J., Laurens M. Bouwer L. M., Pflug, G., Rojas R., and Philip J. Ward P.J. (2014). Increasing stress on disaster-risk finance due to large floods. Nature Climate Change 4, pp. 264-268. doi:10.1038/nclimate2124.
2. Chendeş V., Bălteanu D., Micu D., Sima M., Ion B., Grigorescu I., Persu M., Dragotă C. (2015). A database design of major past flood events in Romania from national and international inventories, Air and Water Components of the Environment (Cluj-Napoca), pp. 25-32.

3. Commission of the European Communities. (2007). Addressing the challenge of water scarcity and droughts in the European Union. COM, 414 p.

4. Croitoru, A.E. and I. Minea. (2015). The impact of climate changes on rivers discharge in Eastern Romania. Theoretical and Applied Climatology, 120: pp. 563-573.

5. Busuioc, A., Dobrinescu, A., Birsan, M,V., Dumitrescu, A. and A. Orzan. (2015). Spatial and temporal variability of climate extremes in Romania and associated large-scale mechanisms. International Journal of Climatology, 35: pp. 1278-1300.

6. CEOS, 2015. Satellite Earth Observations in Support of Disaster Risk Reduction. The CEOS Earth Observation Handbook, Special 2015 Edition for the 3rd UN World Conference on Disaster Risk Reduction.

7. Negula D, Crăciunescu V, Vîrsta A, Badea A, Moise C, Manea R, Călin M, Irimescu A. (2013). Downstream Copernicus Service for Emergency Management in Romania. Proceedings of 13th SGEM GeoConference on Informatics, Geoinformatics And Remote Sensing, vol. 1, Albena, Bulgaria, pp. 403 - 410.

8. Duong, N., D,. Water Body Extraction from Multi Spectral Image by Spectral Pattern Analysis. (2012). Intern. Archives of the Photogramm., Remote Sens. and Spatial Information Sciences, vol. XXXIX-B8, XXII ISPRS Congress, Melbourne, Australia.

9. Lu, D.; Weng, Q. (2007). A survey of image classification methods and techniques for improving classification performance. Int. J. Remote Sens., $\mathbf{2 8}$, pp. $823-870$.

10. Richards, J., A. Remote Sensing Digital Image Analysis: An Introduction. (2012). Springer Science \& Business Media, 9, pp. 494.

11. Frazier, P.S.; Page, K.J. (2000). Water body detection and delineation with Landsat TM data. Photogramm. Eng. Remote Sens., 66, pp. 14611468.

12. Amarnath, G. An algorithm for rapid flood inundation mapping from optical data using a reflectance differencing technique. (2014). Journal of Flood Risk Management, vol. 7, issue 3, pp. 239250.

13. Boschetti,M., Nutini, F., Manfron,G., Alessandro, P., Brivio, P. and Andrew Nelson, A. (2014). Comparative Analysis of Normalised Difference Spectral Indices Derived from MODIS for Detecting Surface Water in Flooded Rice Cropping Systems. PLoS One. 2014; 9(2): e88741. Published online 2014 Feb 20. doi: 10.1371/journal.pone.0088741.

14. $\mathrm{Xu}, \mathrm{H}$. (2006). Modification of normalised difference water index (NDWI) to enhance open water features in remotely sensed imagery. 
Int. J. Remote Sens. 27: 3025-3033doi:10.1080/ 01431160600589179.

15. McFeeters, S. The use of the Normalized Difference Water Index (NDWI) in the delineation of open water features. (1996). Int. J. Remote Sens., 17, pp. 1425-1432.

16. Xu, H. Modification of normalised difference water index (NDWI) to enhance open water features in remotely sensed imagery. (2006). Int. J. Remote Sens., 27, 3025-3033.

17. Schubert, A., Jehle, M., Small, D. and Meier, E. (2010). Influence of atmospheric path delay on the absolute geolocation accuracy of TerraSAR-X highresolution products. IEEE Trans. Geosci. Remote Sens., vol. 48, no. 2, pp. 751-758.

18. Pulvirenti, L.,. Chini, M, Pierdicci, N., Guerriero, L. and Ferrazzoli, P. (2011). Flood monitoring using multi-temporal COSMO-SkyMed data: Image segmentation and signature interpretation. Remote Sens. Environ., vol. 115, no. 4, pp. 990-1002.

19. Crăciunescu V, Flueraru C, Anderson E, Nedelcu I, Stăncălie G, Irimescu A. (2009). Mapping and monitoring the 2005-2008 floods in Romania, using remote sensing techniques. Complexul Muzeal Bistrita Nasaud "Studii si Cercetari": Geology Geography, 14, pp. 107-122.

\section{Acknowledgements}

This work was supported by a Grant of the Romanian National Authority for Scientific Research, CNDIUEFISCDI, "Platform for GeoInformation in Support of Disaster Management - GEODIM", (ID PN-II-PTPCCA-2011-3.2-057), project nr. 202/2012. 